\title{
Sexual Function and Dyadic Adjustment in Infertile Women
}

\author{
İnfertilite Sorunu Yaşayan Kadınlarda Cinsel İşlev Durumu ve Çift \\ Uyumu
}

\author{
Ferda Kaba ${ }^{* 1}$, Nuray Egelioğlu Cetişli $i^{2}$
}

\begin{abstract}
Introduction: Infertility is a painful and emotionally stressful life crisis due to the processes performed in the infertility treatment process. Couples can cause problems in marriage relations, sexual dysfunctions and couple relationships by forcing stress coping skills and social support resources in this process. This study was conducted to evaluate the sexual function status and the couple match level of women that have infertility problems. Method: 169 infertile women, who were applied to the IVF center of an educational research hospital in Izmir, were accepted in the sample set of the study that is descriptive and relational type Data were collected by the Golombock-Rust Inventory Sexual Satisfaction-Female Form (GRISS) and the Dyadic Adjustment Scale (DAS) with face-to-face interviews of infertile women. Mann Whitney U, Kruskal Wallis test and correlation analysis were used in data analysis. Results: The mean age of women was $29,8 \pm 3,0$ years and the mean marriage duration was $5,3 \pm 2,2$ years. $54,4 \%$ of them were high school graduates, $57,4 \%$ of them were not working, $41,4 \%$ of them did not know the cause of infertility and $85,2 \%$ of them were primary infertile. The total DAS score of women was $91,2 \pm 19,4$ and the total GRISS score was $5,3 \pm 1,4$. In the study, a negative significant correlation was found at medium level between the total DAS score and GRISS score of infertile women participated in the study $(r=-0,65, p=0,00)$. However a significant correlation between the marriage duration of the women and the duration of requesting the children and GRISS and DAS total score was found, there was difference only between the total DAS score regarding the type of infertility and its cause. Conclusion: It was found in this study that women, who had infertility diagnosis, experienced sexual dysfunction fewer as their couple adjustment increases. Health professionals at any stage of health service should evaluate the family holistically not only the woman that effected by the infertility. They should make right overtures about revealing effect of infertility on couples and their sexual life.
\end{abstract}

Key words: Infertility, sexual function, dyadic adjustment

\section{ÖZET}

Giriş: İnfertilite, tedavi sürecinde yapılan işlemler nedeniyle acı verici ve duygusal olarak stresli bir yaşam krizine neden olmaktadır. Bu süreç, çiftlerin stresle başa çıkma becerilerini ve sosyal destek kaynaklarını zorlayarak evlilik ilişkilerinde problemler yaşamalarına, cinsel işlev bozukluklarına, ilişkilerinde bozulmalara neden olabilmektedir. Bu çalışma, infertil kadınların cinsel işlev durumu ve çift uyumu düzeylerinin değerlendirilmesi amacıyla yürütülmüştür. Yöntem: Tanımlayıcı ve ilişkisel tipteki araştırmanın örneklemini, İzmir'de bir eğitim araştırma hastanesinin Tüp Bebek Merkezi'ne başvuran, araştırmaya dâhil edilme kriterlerine uyan, 169 infertil kadın oluşturmuştur. Veriler, infertil kadınlar ile yüz yüze görüşülerek Birey Tanıtım Formu, Golombock-Rust Cinsel Doyum Ölçeği-Kadın Formu (GRCDÖ) ve Dyadik Çift Uyum Ölçeği (DÇUÖ) kullanılarak toplanmıştır. Verileri değerlendirmek amacıyla Mann Whitney U, Kruskal Wallis testi ve korelasyon analizi kullanılmıștır. Bulgular: Kadınların yaş ortalaması $29,8 \pm 3,0$ yıl ve evlilik süresi 5,3 $\pm 2,2$ y1l olup, \%54,4'ü lise mezunu, \%57,4'ü çalışmıyor, \%41,4'ü infertilite nedenini bilmemekte ve \%85,2'si primer infertildir. Kadınların DÇUÖ toplam puan ortalamas $91,2 \pm 19,4$, GRCDÖ toplam puan ortalaması ise 5,3 $\pm 1,4$ 'dir. Çalışmaya katılan infertil kadınların GRCDÖ toplam puan ortalamaları ile DÇUÖ toplam puan ortalamaları arasında negatif yönde orta düzeyde anlamlı bir ilişki olduğu tespit edilmiştir $(\mathrm{r}=-0,65, \mathrm{p}=0,00)$. Kadınların evlilik süresi ve çocuk isteme süreleri ile GRCDÖ ve DÇUÖ toplam puan ortalamaları arasında ilişki varken, infertilite tipine ve nedenine göre sadece DÇUÖ toplam puan ortalamaları arasında anlamlı fark vardır. Sonuç: Araştırmada, infertilite tanısı alan kadınların çift uyumlarının artması ile, cinsel işlevlerinde bozulmayı daha az yaşadıkları belirlenmiştir. Sağlık hizmetinin, tüm basamaklarındaki sağlık çalışanları sadece infertiliteden etkilenen kadını değil, aileyi bir bütün olarak değerlendirmeye almalı ve infertilitenin çift ilişkisi ve cinsel yaşam üzerine etkisini açığa çıkartabilecek doğru yaklaşımlarda bulunmalıdır.

Anahtar kelimeler: İnfertilite, cinsel işlev, çift uyumu

Received Date / Geliş Tarihi: 11.07.2018 Accepted Date / Kabul Tarihi: 27.08.2018

${ }^{1}$ Ege Üniversitesi Tıp Fakültesi Hastanesi

${ }^{2}$ İzmir Katip Çelebi Üniversitesi Sağlık Bilimleri Fakültesi Hemşirelik Bölümü

*Address for Correspondence / Yazışma Adresi: Nuray EGELİOĞLU CETİŞLİ, İzmir Katip Çelebi Üniversitesi Sağlık Bilimleri

Fakültesi Hemşirelik Bölümü E-mail: nurayegelioglu@gmail.com

Kaba F, Cetişli NE. İnfertilite, Cinsel İşlev ve Çift Uyumu. TJFMPC, 2019;13 (1): 28-33. DOI:- 10.21763/tjfmpc.527975 


\section{GíRiș}

İnfertilite, bireyler için psikolojik, tıbbi ve sosyal problemleri beraberinde getiren, kültürel, dinsel ve sınıfsal yönleri olan, eşler arası cinsel uyumsuzluğa ve yetersizlik hissine yol açabilen, beklenmeyen stresörlerle karşılaştıran, toplumsal etiketlenmeyle sonuçlanan bir deneyimdir. ${ }^{1,} 2$ Toplumumuzda çocuk sahibi olmak, evliliğin temel işlevi olarak kabul edilmekte ve bu nedenle çocuk sahibi olmak bireylerin yaşamlarının önemli aşamalarından biri olarak görülmektedir. Çiftlere çocuk sahibi olmaları konusunda yapılan baskılar, çocuksuz olmanın yetersizlik olarak düşünülmesi, toplumda infertiliteyi önemli bir sorun haline getirmektedir. ${ }^{3,} 4$ İnfertilite, çiftler açısından psikolojik yönden tehdit edici, tedavi sürecinde yapılan işlemler nedeniyle acı verici ve duygusal olarak stresli bir yaşam krizi olmakta, çiftlerin bu süreçte stresle başa çıkma becerilerini ve sosyal destek kaynaklarını zorlayarak evlilik ilişkilerinde problemler yaşamalarına, cinsel işlev bozukluklarına, çift ilişkilerinde bozulmaya, depresyon ve kaygiya neden olabilmektedir. ${ }^{4-6}$

Çiftlerde, infertilitenin kendisi ve tedavi sürecinin neden olduğu evlilik sorunlarıyla birlikte cinsel işlev problemleri ve cinsel doyumda da sorunlar gelişebilmektedir. Tedavi sürecindeki müdahaleler ve yetersizlik duygusunun kişide yaratmış olduğu stres, cinsel ilişkideki ilgi ve hazzın kaybolmasına neden olmaktadır. Cinsellik ve cinsel aktivitenin, çiftler arasındaki samimiyet ve yakınlı hislerinin gösterilmesinde ve eş ilişkisinde önemli rolü vardır. ${ }^{7,8}$ Cinsellik ve üreme kavramının çoğu çift için iç içe geçmiş olması, çiftlerin daima menstrüel döngü ve ovulasyon ile ilgili süreçleri takip etme durumunda kalmaları, cinselliği üreme amacından kurtaramamaktadır. Özellikle siklusun fertil zamanlarında ilişkiye girme zorunluluğu, cinsel ilişkinin doğallığının bozulmasına neden olmaktadır. Literatürde, infertilitenin evlilik uyumu ve cinsel işlevler üzerine etkisini araştıran çalışmalardan elde edilen sonuçların çelişkili olduğu görülmektedir. Yapılan araștırmalarda, infertilitenin hem kadın hem de erkekte cinsel doyumu azalttığ tartışmaları arttırabildiği gibi, çiftleri yakınlaştırdığı ve evliliği güçlendirebildiği de belirtilmektedir. ${ }^{9-12}$ İnfertilite sürecinde tanı aşamasından başlayarak, infertilitenin psikososyal ve psikoseksüel etkilerini göz ardı etmeden çiftin gereksinimlerini değerlendirebilmek ve çifte özel yaklaşımda bulunabilmek son derece önemlidir. Cinsellik, bireylerin paylaşmakta güçlük yaşadığı ve sağlık çalışanları tarafından da gündeme getirilmesi zor bir konu olması sebebiyle bireylerin şikâyetlerini rahatlıkla dile getirmelerini ve yardım almalarını olumsuz yönde etkilemiştir. Sağlık çalışanları infertilite ve sorunlarına yönelik bireylerin yaşam kalitesinin arttırılmasında, evlilik ilișkilerini önemli derecede etkileyen cinsel sorunlarının ve aile içi iletişim problemlerinin çözümlenmesinde bireylere danışmanlık yapmalıdırlar. ${ }^{11,13,14}$

$\mathrm{Bu}$ araştırmanın amacı, infertil kadınların cinsel işlev durumu ve çift uyumu düzeylerinin belirlenmesidir.

\section{YÖNTEM}

Tanımlayıcı ve ilişkisel araştırma türüne uygun olarak, Mart-Mayıs 2018 tarihleri arasında İzmir'de bir eğitim ve araştırma hastanesinin Tüp Bebek Merkezi'nde yürütülen çalışmada, araştırmanın örneklemi, olasılıksız örnekleme yöntemlerinden amaçlı örnekleme yöntemi kullanılarak, örneklem büyüklüğü ise evreni bilinmeyen gruplarda örneklem büyüklüğü hesaplama formülü ile belirlenmiştir. Ülkemizde infertilite görülme sıklığ literatürde $\% 10$ olarak belirtilmiştir. ${ }^{3}$ Bu nedenle, olayın görülme sıklığı \%10 olarak alındığında çalışma için 139 kadının yeterli olacağı belirlenmiş olup, Tüp Bebek Merkezi'ne başvuran infertilite tanısı almış, 18 yaş üzerinde, evli, Türkçe konuşabilen ve anlayabilen, kronik herhangi bir hastalığa sahip olmayan, tanı almış psikolojik problemi olmayan ve çalışmaya katılmayı kabul eden 169 kadın ile yürütülmüştür.

Araştırma verilerini toplamak için, Birey Tanıtım Formu, Golombock-Rust Cinsel Doyum Ölçeği-Kadın Formu (GRCDÖ) ve Dyadik Çift Uyum Ölçeği (DÇUÖ) kullanılmıştır.

Birey Tanıtım Formu: İnfertilite tanısı almış kadınların sosyo-demografik özellikleri ve infertilite öykülerine ilişskin bilgilerinin elde edilmesi amacıyla literatürden yararlanılarak, araştırmacılar tarafindan hazırlanan form 12 sorudan oluşmaktadır. ${ }^{8-12}$

Golombok-Rust Cinsel Doyum Ölçeği-Kadın Formu: Cinsel ilișkinin niteliğini ve cinsel ișlev bozukluklarını değerlendirmek amacı ile, Rust ve Golombock tarafindan (1986) geliştirilmiş ve Tuğrul ve arkadaşları (1993) tarafından Türkçe geçerlilik güvenirliği yapılmış bir ölçme aracıdır. Ölçek, 28 maddeden ve yedi alt boyuttan (Kaçınma, Doyum, İletişim, Dokunma, İlişki sıklığı, Vajinismus ve Orgazm bozukluğu) oluşmaktadır. Maddeler, beşli likert tipi derecelendirme ile yanıtlandırılmakta, elde edilen sonuçlar daha sonra 1 ile 9 arasında değişen standart puanlara (5 kesme noktasıdır) çevrilerek, 5 puan ve üzerinde puan alan katılımcılar "sorunlu grup (cinsel ilişkinin veya işlevlerde bozulma)", 5 puan altında alanlar "sorunsuz grup" olarak tanımlanmaktadır. Ölçeğin Cronbach alpha katsayısı, Rust ve Golombok tarafindan 0,87 , Tuğrul ve arkadaşları tarafindan 0,91 olarak bulunmuştur. ${ }^{15} \mathrm{Bu}$ çalışmada ise, ölçeğin Cronbach alpha katsayısı 0,82'dir.

Dyadik Çift Uyum Ölçeği: Türkçe geçerlilik güvenirlik çalışması Fişıloğlu ve Demir (2000) tarafindan yapılmış, Spanier (1976) tarafindan ise evlilikteki uyumu, evliliğin niteliğini ve uyumun kalitesini ölçmek için geliștirilmiş olan ölçek, evli veya birlikte yaşayan çiftlere uygulanabilen likert tipi bir ölçektir. Toplam 32 madde ve dört boyuttan (çift uyumu, çift doyumu, sevgi gösterme ve çiftlerin bağlılı̆̆ 1 ) oluşan ölçekten elde edilen puanlar 0 ile 151 arasında değişmekte olup, toplam puanın yüksek olması evlilikte uyumun iyi olduğunu göstermektedir. Ölçeğin, Cronbach alpha iç tutarlılık değeri Spainer tarafından 0,96, Fışıloğlu ve Demir tarafından 0,92 olarak bulunmuştur. ${ }^{16} \mathrm{Bu}$ çalışmada ise ölçeğin Cronbach alpha katsayısı 0,91 'dir.

Araştırmadan elde edilen verilerin analizi, Statistical Package for the Social Sciences (SPSS) 20.0 istatistik paket programında gerçekleştirilmiştir. Çalışmaya katılan kadınların sosyo-demografik özellikleri, sayı ve yüzde dağılımları olarak verilmiştir. Bireylerin sosyo-demografik özelliklerine göre, GRCDÖ ve DÇUÖ puan ortalamalarını incelemek amacıyla 
normal dağılıma uygunluk analizleri yapılmış ve verilerin normal dağılıma uymadığı belirlenmiş, nonparametrik testler (Mann Whitney $U$ ve Kruskal Wallis) kullanılmıştır. Kadınların GRCDÖ ve DÇUÖ puan ortalamaları arasındaki ilişkiyi incelemek için korelasyon analizi yapılmıştır. Tüm istatistiksel analizlerde $p<0,05$ anlamlılık düzeyi temel alınmıştır.

Veriler, örnekleme alınan kadınlardan yüz yüze görüşme tekniği ile yaklaşık 15 dakikalık sürede, kadınların mahremiyetini ve kendilerini daha rahat ifade edebilmelerini sağlamak amaciyla klinikte yer alan hasta görüşme odasında toplanmıştır. Araştırmanın yürütülebilmesi için Etik Kurul (tarih: 29.11.2017, karar no:258), kurum izinleri ve katılımcılardan yazılı onam alınmıştır.

\section{BULGULAR}

Çalışmaya katılan kadınların yaş ortalaması 29,8 2 3,0 yıl, evlilik süresi ortalaması $5,3 \pm 2,2$ yıl ve çocuk isteme süresi ortalamas $13,4 \pm 1,4$ y1l olup, $\% 54,4$ 'ü lise mezunu, $\% 57,4$ 'ü çalışmıyor, \%58'inin geliri giderine denk, $\% 94,1$ 'inin sosyal güvencesi var, \%41,4'ü nedeni bilinmeyen infertilite ve \%85,2'si primer infertilite tanısına sahiptir. Kadınların yaş, evlilik süresi ve çocuk isteme süresi ortalamaları ile GRCDÖ toplam puan ortalaması arasında pozitif yönde istatistiksel olarak anlamlı zayıf ilişki, DÇUÖ toplam puan ortalamaları arasında da negatif yönde zayıf ilişki vardır. Çalışan kadınların, çalışmayanlara göre çift uyumunun daha yüksek $(\mathrm{z}=2,38, \mathrm{p}=0,01)$ olduğu, geliri giderinden az olan kadınların ise geliri giderine eşit ve fazla olan kadınlara göre cinsel işlevlerinde daha fazla bozulma olduğu $\left(\mathrm{x}^{2}=10,80, \mathrm{p}=0,00\right)$ belirlenmiştir. Kadınların infertilite nedenlerine ve tiplerine göre GRCDÖ puan ortalamaları arasında fark bulunmazken $(\mathrm{p}>0,05)$, primer infertilite tanısı alan kadınların DÇUÖ toplam puan ortalamalarının sekonder infertil kadınlara göre daha yüksek $(\mathrm{z}=-2,26$, $\mathrm{p}=0,02)$, nedeni bilinmeyen infertilitesi olan kadınların da diğer infertilite nedenlerine sahip kadınlara göre daha düşük DÇUÖ toplam puan ortalamalarına sahip olduğu $\left(\mathrm{x}^{2}=8,70, \mathrm{p}=0,01\right)$ belirlenmiştir (Tablo 1$)$.

Çalışmaya katılan kadınların, GRCDÖ ve DÇUÖ toplam ve alt ölçek puan ortalamaları ile ölçekler arasındaki ilişki Tablo 2'de yer almaktadır. İnfertil kadınların GRCDÖ toplam puan ortalaması 5,3 $\pm 1,4$ olup, Dokunma, Vajinismus, Kaçınma ve İletişim alt ölçeklerinde sorun olduğu belirlenmiştir. Kadınların DÇUÖ toplam puan ortalaması 91,2 $\pm 19,4$ olup, Çift Uyumu alt ölçeği puan ortalamas1 39,5 $\pm 11,1$, Çift Doyumu alt ölçeği puan ortalaması 31,5 $\pm 5,6$, Sevgi Gösterme alt ölçeği puan ortalaması $7,8 \pm 2,1$ ve Çiftlerin Bağlılığ alt ölçeği puan ortalaması $12,2 \pm 2,8$ 'dır. Çalışmaya katılan infertil kadınların GRCDÖ ile DÇUÖ toplam ve alt ölçek puan ortalamaları arasında negatif yönde ilişki olduğu belirlenmiştir $(\mathrm{p}<0,05)$. Bu sonuç çalışmaya katılan infertilite tanısı alan kadınların evliliklerinde çift uyumlarının artmasıyla, cinsel ilişki veya işlevlerde bozulmayı daha az yaşadıklarını göstermektedir (Tablo 2).

\section{TARTIŞMA}

İnfertil kadınların, cinsel işlev ve çift uyumu düzeylerinin belirlenmesi amacıyla yürütülen çalıșmada, kadınların yaş ortalamaları, evlilik süresi ve çocuk isteme süreleri arttıkça cinsel doyumlarında artma, fakat çift uyumlarında azalma olduğu belirlenmiştir. Cetişli ve arkadaşları tarafından, primer infertil kadınlar ile yapılan çalışmada yaş ve çift uyumu ve cinsel işlev arasında ilişki bulunmazken, evlilik süresinin artmasının cinsel doyum ve çift uyumunu arttığ 1 sonucu elde edilmiştir. ${ }^{11}$ Güleç ve arkadaşlarının çalışmasında, çiftlerin evlilik süresi uzadıkça cinsel doyumlarının azaldığı, Bodur ve arkadaşları, Repokari ve arkadaşları ve Taşçı ve arkadaşlarının çalışmalarında ise, evlilik süresine göre çift uyumları arasında fark olmadığ 1 saptanmıştır. ${ }^{10,}$ 17-19 İnfertilite tedavisinin pahalı ve uzun zaman alan bir tedavi olması ve tedavi sonucunun belirsiz olması sebebiyle, tedavi sürecinde eşler kendilerini dönem, dönem veya sürekli kötü hissedebilmektedir. Yaş, evlilik süresi ve çocuk isteme süresi arttıkça, eşler arasındaki suçlamalar ve evlilik uyumlarındaki bozulmalar belirginleşebilmekte ve eşler arasındaki sevgi bağları zayıflayarak, çift ilişkisi bozulabilmektedir.

Bu çalışmada, çalışan kadınların çift uyumlarının daha yüksek olduğu belirlenmiştir. Şen ve arkadaşlarının, primer infertil kadınlarda eşler arası uyumu incelemek amacıyla yürüttükleri çalışmada, çalışan kadınların çift uyumlarının daha yüksek olduğu sonucu elde edilmiştir. ${ }^{9}$ Literatürdeki diğer çalışmalarda da, çalışan kadınlarda evlilik uyumunun arttığı saptanmıștır. ${ }^{17,} 20$ Bireylerin, özellikle de kadınların çalıştığı iş yerinde yeni bir şeyler üreterek toplumda statü kazanması, kendini verimli hissetmesi psikolojik sağlığını olumlu yönde etkilemektedir. Ayrıca ekonomik anlamda kendini özgür hissetmesini sağlamaktadır. ${ }^{21} \mathrm{Bu}$ doğrultuda çalışmaya katılan, infertilite sorunu yaşayan, çalışan kadınların çift uyumlarının daha yüksek olmasının, çalışma hayatının psikolojik sağlıklarını olumlu yönde etkilemesi ve baş etme becerilerini geliştirmesi ile ilişkili olabileceği düşünülmektedir. Çalışmada, geliri-giderinden az olan kadınların cinsel işlev bozukluğunun daha fazla olduğu belirlenmiştir. Yapılan çalışmalarda da, düşük gelir düzeyine sahip infertil kadınların daha fazla cinsel sorun yașadıkları bildirilmiştir., ${ }^{4} 10$ Elde edilen sonuçların, tedavi masraflarından dolayı ekonomik olarak güçlük çeken çiftlerin cinselliklerini sadece çocuk sahibi olmak üzerine odaklamaları, cinsel isteklerini ve cinsel tatminlerini ikinci plana atmaları ile ilişkili olabileceği düşünülmektedir.

Çalışmada, primer infertilite tanısı alan kadınların çift uyumlarının, sekonder infertil kadınlara oranla daha yüksek düzeyde olduğu bulunmuştur. Çiftler, infertilite sürecini bir tehdit gibi algilayarak birbirlerine daha da yakınlaşabilmekte ve infertilite sebebiyle meydana gelen sorunları, tedavi ile ilgili kararları paylaşarak birbirlerine destek sağlayabilmektedirler. Çalışmada, nedeni bilinmeyen infertilitesi olan kadınların çift uyumlarının düşük olduğu saptanmıştır. Benzer şekilde, Bodur ve arkadaşlarının çalışmasında da kadınlarda çift uyumunun açıklanamayan infertilite durumunda düşük olduğu belirlenmiştir. ${ }^{17}$ Çocuk sahibi olma yeteneği toplumlarda hala önemli bir pozisyonda bulunmakta ve bu yeteneğin bozulmasından kadın sorumlu tutulmaktadır. Problemin, her iki ește de olmasının kadının yükünün hafiflemesine, sorunun paylaşılmasına ve özellikle de eşi ve eşinin ailesi tarafından daha az damgalanmasına sebep olabileceği düşünülmektedir. 


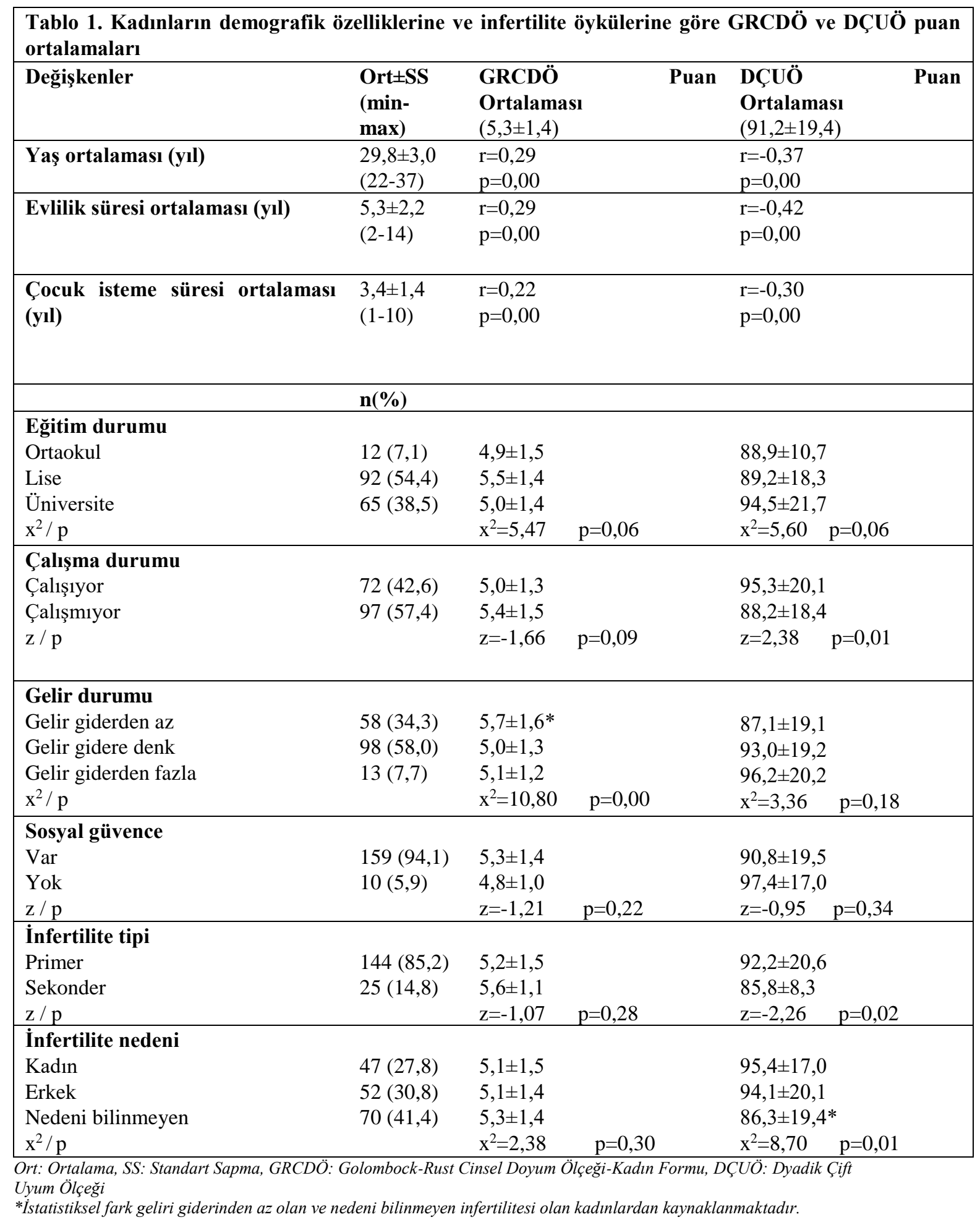




\begin{tabular}{|c|c|c|c|c|c|}
\hline GRCDÖ & $\begin{array}{l}\text { DÇUÖ } \\
\text { Toplam Puan } \\
(91,2 \pm 19,4)\end{array}$ & $\begin{array}{l}\text { Çift Uyumu } \\
(39,5 \pm 11,1)\end{array}$ & $\begin{array}{l}\text { Çift Doyumu } \\
(31,5 \pm 5,6)\end{array}$ & $\begin{array}{l}\text { Sevgi Gösterme } \\
(7,8 \pm 2,1)\end{array}$ & $\begin{array}{l}\text { Çiftlerin } \\
\text { Bağlılığı }(12,2 \pm 2,8)\end{array}$ \\
\hline $\begin{array}{l}\text { Toplam Puan } \\
(5,3 \pm 1,4)\end{array}$ & $\begin{array}{l}r=-0,65 \\
p=0,00\end{array}$ & $\begin{array}{l}r=-0,54 \\
p=0,00\end{array}$ & $\begin{array}{l}\mathrm{r}=-0,69 \\
\mathrm{p}=0,00\end{array}$ & $\begin{array}{l}r=-0,61 \\
p=0,00\end{array}$ & $\begin{array}{l}\mathrm{r}=-0,48 \\
\mathrm{p}=0,00\end{array}$ \\
\hline $\begin{array}{l}\text { Sıklık } \\
(4,7 \pm 0,8)\end{array}$ & $\begin{array}{l}\mathrm{r}=-0,52 \\
\mathrm{p}=0,00\end{array}$ & $\begin{array}{l}\mathrm{r}=-0,40 \\
\mathrm{p}=0,00\end{array}$ & $\begin{array}{l}r=-0,59 \\
p=0,00\end{array}$ & $\begin{array}{l}r=-0,50 \\
p=0,00\end{array}$ & $\begin{array}{l}\mathrm{r}=-0,45 \\
\mathrm{p}=0,00\end{array}$ \\
\hline $\begin{array}{l}\text { İletişim } \\
(5,1 \pm 1,7)\end{array}$ & $\begin{array}{l}r=-0,46 \\
p=0,00\end{array}$ & $\begin{array}{l}r=-0,32 \\
p=0,00\end{array}$ & $\begin{array}{l}r=-0,54 \\
p=0,00\end{array}$ & $\begin{array}{l}r=-0,38 \\
p=0,00\end{array}$ & $\begin{array}{l}r=-0,49 \\
p=0,00\end{array}$ \\
\hline $\begin{array}{l}\text { Doyum } \\
(3,9 \pm 1,3)\end{array}$ & $\begin{array}{l}r=-0,68 \\
p=0,00\end{array}$ & $\begin{array}{l}\mathrm{r}=-0,57 \\
\mathrm{p}=0,00\end{array}$ & $\begin{array}{l}\mathrm{r}=-0,70 \\
\mathrm{p}=0,00\end{array}$ & $\begin{array}{l}r=-0,64 \\
p=0,00\end{array}$ & $\begin{array}{l}\mathrm{r}=-0,54 \\
\mathrm{p}=0,00\end{array}$ \\
\hline $\begin{array}{l}\text { Kaçınma } \\
(5,6 \pm 1,1)\end{array}$ & $\begin{array}{l}r=-0,55 \\
p=0,00\end{array}$ & $\begin{array}{l}r=-0,47 \\
p=0,00\end{array}$ & $\begin{array}{l}r=-0,58 \\
p=0,00\end{array}$ & $\begin{array}{l}r=-0,54 \\
p=0,00\end{array}$ & $\begin{array}{l}r=-0,33 \\
p=0,00\end{array}$ \\
\hline $\begin{array}{l}\text { Dokunma } \\
(7,2 \pm 0,7)\end{array}$ & $\begin{array}{l}r=-0,54 \\
p=0,00\end{array}$ & $\begin{array}{l}r=-0,47 \\
p=0,00\end{array}$ & $\begin{array}{l}r=-0,55 \\
p=0,00\end{array}$ & $\begin{array}{l}r=-0,52 \\
p=0,00\end{array}$ & $\begin{array}{l}r=-0,37 \\
p=0,00\end{array}$ \\
\hline $\begin{array}{l}\text { Vajinismus } \\
(6,3 \pm 1,3)\end{array}$ & $\begin{array}{l}\mathrm{r}=-0,32 \\
\mathrm{p}=0,00\end{array}$ & $\begin{array}{l}\mathrm{r}=-0,27 \\
\mathrm{p}=0,00\end{array}$ & $\begin{array}{l}\mathrm{r}=-0,35 \\
\mathrm{p}=0,00\end{array}$ & $\begin{array}{l}\mathrm{r}=-0,32 \\
\mathrm{p}=0,00\end{array}$ & $\begin{array}{l}\mathrm{r}=-0,17 \\
\mathrm{p}=0,00\end{array}$ \\
\hline
\end{tabular}

GRCDÖ: Golombock-Rust Cinsel Doyum Ölçeği-Kadın Formu DÇUÖ: Dyadik Çift Uyum Ölçeği

İnfertilite sorunu yaşayan kadınlarda, cinsel ișlev durumu ve çift uyumu düzeylerinin değerlendirilmesini amaçlayan bu çalışmada, kadınların çift uyumlarının iyi düzeyde olduğu belirlenmiştir. Farklı ülkelerde yapılan çalışmalarda, infertil kadınların çift uyumunun düşük olduğu, çocuk sahibi olamamanın kadınlarda yarattığı suçluluk, stres, kaygı ve toplumsal baskının çiftler arasında problemler yaşanmasına ve evlilikte çift uyumlarının bozulmasına sebep olabileceği bildirilmiştir. ${ }^{10,11,21}$ Literatürde, konu ile ilgili yapılan diğer bazı çalışmalarda da infertil kadınların çift uyum düzeyleri yüksek bulunmuş ve infertilitenin tedavi sürecinin ve sebep olduğu krizin uzun yıllar eşler arasında paylaşılması, birbirlerine olan desteklerinin artmasına, eşlerin yakınlaşmasına ve evliliklerinin güçlenmesine neden olabileceği bildirilmiştir. ${ }^{9}, 17,23 \mathrm{Bu}$ çalışmada $\mathrm{da}$, güncel literatüre benzer bulguların elde edilmesi, infertilitenin çiftleri yakınlaştırdığı, kararların ortak verilmesi ile birbirlerine olan desteğin artmas1 sonucu çift ilişkilerinin gelişimine katkıda bulunduğu sonucunu destekler niteliktedir.

Çalışmada, cinsel hayatın niteliğini değerlendiren GRCDÖ toplam puanlarında ve dokunma, iletişim, kaçınma ve vajinismus alt ölçeklerinde sorun olduğu belirlenmiştir. Cinsel ilişkide partnerlerin beklentilerini söylemesi ve karşıllklı olarak isteklerini belirtmesi cinsel doyum için çok önemli bir etkendir. ${ }^{12}$ Cinsel iletişim, cinsel işlev bozukluklarında büyük rol oynamaktadır. Yapılan araştırmalar, cinsel iletişim eksikliklerinin cinsel işlev bozukluklarının etiyolojisinde ve devam etmesinde önemli bir etken olduğunu, hatta tedavi sonuçlarını da etkileyebildiğini göstermektedir. ${ }^{14,}{ }^{22,} \quad{ }^{23} \quad$ Babin çalışmasında, bireylerin cinsellik ile ilgili sözel veya sözel olmayan iletişimi sağlamalarının, kendilerine olan güveni ve cinsel doyumu arttırdığını tespit etmiştir. ${ }^{24}$ Cetişli ve arkadaşlarının çalışmasında, kaçınma, dokunma, vajinismus alt ölçeklerinde, Karlıdere ve arkadaşlarının çalışmasında, sıklık ve kaçınma alt ölçeklerinde, Güleç ve arkadaşlarının çalışmasında ise, anorgazmi ve vajinismus alt ölçeklerinde sorun saptanmıştır. ${ }^{10,11,25} \mathrm{Bu}$ çalışmada da, kadınların zamanlanmış cinsel ilişkide bulunmaları, ilişkide üreme amacının olması, kendilerini baskı altında hissetmeleri sebebiyle kadınlarda daha çok ilişkiden kaçınma, cinsel istek kayb1 ve vajinismus şeklinde kendini gösteren cinsel disfonksiyon meydana gelmiş olabileceği düşünülmektedir.

Çalışmaya katılan infertil kadınların evliliklerinde, çift uyumlarının artmasıyla, cinsel işlevlerinde bozulmayı daha az yaşadıkları saptanmıştır. Cetişli ve arkadaşları, Valsangkar ve arkadaşları tarafından yapılan çalışmalarda da, cinsel doyum ve çift uyumu arasında ilişki saptanırken, Güleç ve arkadaşları, Monga ve arkadaşları tarafından yapılan çalışmalarda, cinsel doyum ve çift uyumu arasında ilişki bulunmadığ 1 bildirilmiştir. ${ }^{10,} 11,22,23$ İnfertilite evlilik ve dolayısıyla cinsel hayatı etkileyen bir durumdur. Cinsellik ve cinsel aktivite, eşler arasındaki ilişkide, yakınlık ve samimiyet hislerinin sergilenmesinde önemlidir. Çift uyumundaki önemli etmenlerden birinin de cinsel uyum olduğu bildirilmektedir. ${ }^{12,14,19}$ Toplumlarda çocuk sahibi olmak kadın ve erkek için cinsel gücün bir belirleyicisi olabilmekte ve ayrıca çiftler için cinsellik seksten zevk almaktan çok bir çocuk üretmekle ölçülür hale gelebilmektedir. Bu durum kadınlar açısından özür olarak algılanmakta, tanı ve tedavi uygulamaları sirasında meydana gelen anksiyete ve depresyondan kaynaklı bireyler arasında iletişim problemleri ortaya çıkabilmektedir..$^{5-7,13} \mathrm{Bu}$ çalışmada, cinsel doyum ve çift uyumu arasında ilişki bulunmasının nedeninin, infertilitenin çiftler arası iletişimi ve uyumu, cinsel işlev durumunun etkilemesi sonucu oluştuğu düşünülmektedir.

\section{Araştırmanın Sınırlılıkları}

Çalıșmada, kadınların mahremiyetinin sağlanması ve kendilerini açıkça ifade edebilmeleri için anket formları hasta görüşme odalarında doldurulmuş olmasına rağmen, katılımcılar cinsellik ile ilgili sorulara cevap vermede zorlanmışlardır. Ayrıca, araştırmanın İzmir ilindeki bir Tüp Bebek Merkezi'nde yürütülmüş olması, sonuçların genellenebilirliği açısından sinırlılık olarak kabul edilebilir. 


\section{SONUÇ}

İnfertilite görülme sıklığ giderek artan, kadın, aile ve toplumun sağlığını doğrudan etkileyen bir sağlık sorunudur. Çalışmadan elde edilen bulgulara göre, sağlık hizmetinin tüm basamaklarındaki sağlık çalışanları infertilitenin kadın, aile ve toplum sağlığı üzerine olan olumsuz etkilerini gözden kaçırmamak için, sadece

\section{KAYNAKLAR}

1. The American College of Obstetricians and Gynecologists (ACOG). Women's Health Care Physicians Treating İnfertility. 2017. https://www.acog.org/Patients/FAQs/TreatingInfertility\#causes (Erişim tarihi: 14.04.2018).

2. World Health Organization (WHO). Sexual and reproductive health. 2018. http://www.who.int/reproductivehealth/topics/inferti lity/burden/en/ (Erişim tarihi: 14.04.2018).

3. Yılmaz T, Oskay YÜ. İnfertilite stresi ile başa çıkma yöntemleri ve hemşirelik yaklaşımları. HSP 2015;2(1):100-112.

https://doi.org/10.17681/hsp.20993

4. Çoban TK, Dinç A. İnfertilitenin cinsel yaşam üzerine etkisinin incelenmesi. Uluslararası Klinik Araştırmalar Dergisi 2013;1(2):46-53.

5. Mascarenhas MN, Flaxman SR, Boerma $\mathrm{T}$, Vanderpoel S, Stevens GA. National, regional, and global trends in infertility: a systematic analysis of 277 health surveys. PLoS Med 2012;9(12):e1001356.

https://doi.org/10.1371/journal.pmed.1001356

6. Gokler ME, Unsal A, Arslantas D. The prevalence of infertility and loneliness among women aged 1849 years who are living in semirural areas in Western Turkey. Int J Fertil Steril 2014;8(2):155-62.

7. Altıntop İ, Kesgin B. İnfertilite tedavisi gören çiftlerin kaygı, psikolojik dayanıklılık düzeyleri ile başa çıkma stratejileri. Uluslararası Sosyal Araştırmalar Dergisi 2018;11(55):756-768. http://dx.doi.org/10.17719/jisr.20185537247

8. Keskin G, Gümüş AB. İnfertilite: Umutsuzluk perspektifinden bir inceleme. Psikiyatri Hemşireliği Dergisi 2014;5(1):9-16.

9. Şen E, Bulut S, Şirin A. Primer infertil kadınlarda eşler arası uyumun incelenmesi. F.N. Hem. Derg 2014;22(1):17-24.

10. Güleç G, Hassa H, Yalçın EG, Yenilmez Ç. Tedaviye başvuran infertil çiftlerde, infertilitenin cinsel işlev ve çift uyumuna etkisinin değerlendirilmesi. Türk Psikiyatri Dergisi 2011;22(3):166-76. http://dx.doi.org/10.5080 $\underline{\mathrm{U} 6362}$

11. Cetişli NE, Serçekuş P, Oğuz N. Primer infertil kadınlarda cinsel doyum ve çift uyumu. Hemşirelikte Araştırma Geliştirme Dergisi 2014;16(3):38-47

12. Onat G, Kizılkaya Beji N. Effects of infertility on gender differences in marital relationship and quality of life: A case control study of Turkish couples. European Journal of Obstetrics \& Gynecology and Reproductive Biology 2012;165:243-248. https://doi.org/10.1016/j.ejogrb.2012.07.033

13. Aydın S. Kızılkaya Beji N. İnfertil çiftlerde cinsel fonksiyon ve infertilite danışmanının rolü. kadını değil aileyi bir bütün olarak değerlendirmeye almalı ve infertilitenin çift ilişkisi ve cinsel yaşam üzerine etkisini açığa çıkartabilecek doğru yaklaşımlarda bulunmalıdır. Ayrıca, infertil çiftler arasında iletişimin, çift uyumunun ve cinsel işlev sorunlarının azaltılmasına yönelik deneysel çalışmaların da yapılması literatüre katkı sağlayacaktır.

Hemşirelikte Eğitim ve Araştırma Dergisi 2013;10(2):8-13.

14. Tanha FD, Mohseni M, Ghajarzadeh M. Sexual function in women with primary and secondary infertility in comparison with controls. Int J Impot Res 2014:26:132-134 https://doi.org/10.1038/ijir.2013.51

15. Tuğrul C, Öztan N, Kabakcı E. Golombok-Rust Cinsel Doyum Ölçeğinin standardizasyon çalışması. Türk Psikiyatri Derg 1993;4(2):83-88.

16. Fışıloğlu H, Demir A. Applicability of the Dyadic Adjustment Scale of Marital Quality with Turkish Couples. Eur J Psychol Assessment 2000;16:214218. https://doi.org/10.1027//1015-5759.16.3.214

17. Bodur NE, Çoşar $B$, Erdem M. İnfertil çiftlerde evlilik uyumunun demografik ve klinik değişkenlerle ilişkisi. Çukurova Üniversitesi Tıp Fakültesi Dergisi 2013;38(1):51-62.

18. Repokari L, Punamäki RL, Unkila-Kallio L, Vilska $\mathrm{S}$, Poikkeus $\mathrm{P}$, Sinkkonen $\mathrm{J}$, et al. İnfertility treatment and marital relationships: A year prospective study among successfully treated ART couples and their controls. Hum Reprod 2007;22(5):1481-1491. https://doi.org/10.1093/humrep/dem013

19. Taşçı E, Bolsoy N, Kavlak O, Yücesoy F. İnfertil kadınlarda evlilik uyumu. TJOD Derg 2008;2:105110.

20. Donkor ES, Sandall J. The impact perceived stigma and mediating social factors on infertility-related stress among woman seeking infertility treatment in Southern Ghana. Soc Sci Med 2007;65:1683-1694. https://doi.org/10.1016/j.socscimed.2007.06.003

21. Amanak K, Karaöz B, Sevil Ü. Modern yaşamın infertilite üzerine etkisi. TAF Preventive Medicine Bulletin 2014;13:345-50. https://doi.org/10.5455/pmb 1-1368624240

22. Monga M, Alexandrescu B, Katz SE, Stein M, Ganiats T. Impact of infertility on quality of life, marital adjustment, and sexual function. Urology 2004;63(1):126-130. https://doi.org/10.1016/j.urology.2003.09.015

23. Valsangkar S, Bodhare $\mathrm{T}$, Bele S, Sai S. An evaluation of the effect of infertility on marital, sexual satisfaction indices and health-related quality of life in women. Journal of Human Reproductive Sciences 2011;4(2):80-85. https://doi.org/10.4103/0974-1208.86088

24. Babin, EA. An examination of predictors of nonverbal and verbal communication of pleasure during sex and sexual satisfaction. Journal of Social and Personal Relationships 2012;30(3):270-292. https://doi.org/10.1177/0265407512454523

25. Karlıdere T, Bozkurt A, Yetkin S, Doruk A, Sütçigil L, Nahit Özmenler K, ve ark. Psikiyatrik birinci eksen tanısı almayan infertil çiftlerde emosyonel semptomlar, sosyal destek ve cinsel işlev bağlamında cinsiyet farkı var mı? Türk Psikiyatri Dergisi 2007;18(4):311-322. 